\title{
Symmetric Regression Model for Temporal Data
}

\author{
Francisco JA Cysneiros* \\ Departamento de Estatística, CCEN-UFPE - Cidade Universitária, Brazil
}

Submission: December 19, 2017; Published: February 22, 2018

*Corresponding author: Francisco Jose A Cysneiros, Departamento de Estatística, CCEN-UFPE - Cidade Universitaria, Brazil, Email: cysneiros@de.ufpe.br

\begin{abstract}
Gaussian models of times series, ARMA, have been widely used in the literature. In various applications, such as, financial data, the normality assumption is usually adopted. However, when it was not satisfied, some transformation can be adopted for the response variable to obtain, at least, the symmetry property. It is known that the estimates of the coefficients in normal regression models are sensitive to extreme observations. Inferences may be quite imprecise in presence of outliers, especially when it comes to stock return in Latin Americans Markets. One of those alternatives is to consider that the errors have distributions with heavier tails than the normal distribution, in order to reduce the influence of outlier observations. In this work we describe regression models for time series data with non-gaussian errors.
\end{abstract}

Keywords: Non-gaussian distribution; Regression models; Time series

\section{Introduction}

The pioneering work for non-Gaussian time series developed by Heyde \& Feigin [1] who developed Poisson conditional autoregressive range. Cox [2] studied the autocorrelation of data, featuring two classes of time-dependent models: models conditioned on past observations and based on latent processes. In addition, Zeger [3] including the past and present of covariates in this model. Zeger \& Qaqish [4] developed Markov chain for time series. Li [5] included moving averages models component in this model. Pena [6] developed methods to identify influential observations in univariate. Benjamin et al. [7] considered the problem of extending the time series models, ARMA, to data whose conditional distribution given the past of the process belongs to the exponential family (GARMA). Rocha \& CribariNeto [8] developed dynamic models for random variables in the Beta family distribution ( $\beta A R M A)$.

Cao etal. [9] discussheteroscedasticityand/orautocorrelation tests in nonlinear models with AR(1) in symmetric class of distributions. Creal et al. [10] proposed a class of observationdriven time series models named generalized autoregressive score (GAS) models. Details can be found in Kedem \& Fokianos [11]. In the last decade, several results appeared as alternatives to modeling other distributions than the normal errors as, for instance, the symmetrical (or elliptical) distributions. Some of these results can be found in Fang et al. [12] (1990) and Fang $\&$ Anderson [13]. In this perspective, Maior and Cysneiros built upon the class of symmetric distributions an autoregressive moving average symmetrical model, SYMARMA, which is a dynamic model for random variables belonging to the class of symmetric distributions which includes both autoregressive and moving average components, and also includes a set of regressors. They discuss methods for parameter estimation, hypothesis testing and forecasting. A set of computational routines in $\mathrm{R}$ computer language were developed and they can be obtained in www.de.ufpe.br/ cysneiros/elliptical/time series.html.

\section{Acknowledgment}

This research work was partially supported by a CNPq and FACEPE agency from Brazil.

\section{References}

1. Heyde CC, Feigin PD (1975) On efficiency and exponential families in stochastic process estimation. Statistical Distributions in Scientific Work 1: 227-240.

2. Cox DR (1981) Statistical analysis of time series: some recent developments. Scandinavian Journal of Statistics 8: 93-115.

3. Zeger SL (1998) A regression model for time series of counts. Biometrics 75: 621-629.

4. Zeger SL, Qaqish B (1988) Markov regression models for time series: a quasi-likelihood approach. Biometrics 44(4): 1019-1031.

5. Li WK (1994) Time series model based on generalized linear models: some further results. Biometrics 50(2): 506-511.

6. Pena D (1990) Influential observations in time series. Journal of Business and Economic Statistics 8: 235-241.

7. Benjamin MA, Rigby RA, Stasinopoulos M (2003) Generalized autoregressive moving average models. Journal of the American Statistical Association 98: 214-223. 
8. Rocha AV, Neto CF (2009) Beta autoregressive moving average models Test 18: 529-545.

9. Cao CZ, Lin JG, Zhu LX (2010) Heteroscedasticity and/or autocorrelation diagnostics in nonlinear models with $\mathrm{AR}(1)$ and symmetrical errors. Statistical Papers 51(4): 813-836.

10. Creal D, Koopman SJ, Lucas A (2013) Generalized autoregressive score models with applications. Journal of Applied Econometrics 28(5): 777 795
11. Kedem B, Fokianos K (2002) Regression models for time series analysis. New Jersey: Willey.

12. Fang KT, Anderson TW (1990) Statistical Inference in Elliptical Contoured and Related Distributions. New York: Allerton Press, UK.

13. Fang KT, Kotz S, Ng KW (1990) Symmetric multivariate and relates distributions. London, UK.

\section{Your next submission with Juniper Publishers} will reach you the below assets

- Quality Editorial service

- Swift Peer Review

- Reprints availability

- E-prints Service

- Manuscript Podcast for convenient understanding

- Global attainment for your research

- Manuscript accessibility in different formats ( Pdf, E-pub, Full Text, Audio)

- Unceasing customer service

Track the below URL for one-step submission https://juniperpublishers.com/online-submission.php 